\title{
COM O QUE SONHA O LULA? KRENAK SONHA COM LIVES
}

what does Lula dream about? Krenak dreams about lives

¿con qué sueña Lula? Krenak sueña con lives

> Julia Raiz [Universidade Federal do Paraná, Brasil]*

Maré [Artista independente, Brasil]* *

RAIZ, Julia; MARÉ

Com o que sonha o Lula? Krenak sonha com lives. Revista Poiésis, Niterói, v. 23, n. 39 , p. 73-93, jan./jun. 2022.

[DOI: https://doi. org/10.22409/poiesis.v23i39.52946]

Este documento é distribuído nos termos da licença Creative Commons Atribuição Não Comercial 4.0 Internacional (CCBY-NC) (c) 2022 Julia Raiz, Maré.

\section{RESUMO COM O QUE SONHA O LULA? KRENAK SONHA COM LIVES não é só um texto, é uma} sondagem no escuro. A bandeira nos chamou para uma DR. Sonhamos com e sem ela. Depois recolhemos o que deu das não-imagens, não-significações, não-identidades. Tudo no sonho muda como na natureza, todas as formas caminham para a indefinição. COM O QUE SONHA O LULA? KRENAK SONHA COM LIVES é registro da indefinição dos sonhos. Trabalhamos a partir do princípio de Estigmergia. Na estigmergia não existe planejamento prévio, mas um encadeamento de ações que puxam outras ações. A gente vai lá e faz para dar início a uma Ação Oportunista [Ritual Poético], dá um passo atrás pra ver o que aconteceu e depois faz de novo, dando início a outra Ação. Aqui sonhamos como gente e trabalhamos como formigas. A bandeira não disse nada porque a bandeira não existe.

PALAVRAS-CHAVE sonhos; ação oportunista; estigmergia; pensamento decolonial.

\footnotetext{
* Julia Raiz é doutoranda em estudos literários na UFPR. E-mail: julia.raiz@gmail.com. Orcid: https:/ / orcid.org/0000-0003-4966-9568

* * Maré é artista, nordestina y gogoia. E-mail: naomorratriste@gmail.com, @tornadaMare
} 


\section{ABSTRACT WHAT DOES LULA DREAMS ABOUT? KRENAK DREAMS ABOUT LIVES STREAMS is not}

just a text, is probing in the dark. The flag called us to DTR. We dream with and without her. Then we gather what has become non-images, non-meanings, non-identities. Everything in dream changes as in nature, all forms move towards indefiniteness. WHAT DOES LULA DREAMS ABOUT? KRENAK DREAMS ABOUT LIVES STREAMS is a record of the indefiniteness of dreams. We work from the principle of stigmergia. In stigmergy there is no prior planning, but a chain of actions that lead to other actions. We do something to start an Opportunist Action [Poetic Ritual], take a step back to see what happened and then do it again, starting another Action. Here we dream like people and work like ants. The flag didn't say anything because the flag doesn't exist.

KEYWORDS dreams; opportunist action; stigmergia; decolonial thought.

RESUMEN ¿CON QUÉ SUEÑA LULA? KRENAK SUEÑA CON LIVES no es solo un texto, es un sondeo en la oscuridad. La bandera nos llamó por discutir la relación. Soñamos con y sin ella. Luego recopilamos lo que se ha convertido en no-imágenes, no-significados, no-identidades. Todo en el sueño cambia como en la naturaleza, todas las formas se mueven hacia la indefinición. ¿¿CON QUÉ SUEÑA LULA? KRENAK SUEÑA CON LIVES es un registro de la indefinición de los sueños. Trabajamos desde el principio de Estigmergia. En la estigmergia no existe una planificación previa, sino una cadena de acciones que desembocan en otras acciones. Vamos allá y lo hacemos para iniciar una Acción Oportunista [Ritual Poético], damos un paso atrás para ver qué pasó y luego lo volvemos a hacer, comenzando otra Acción. Aquí soñamos como personas y trabajamos como hormigas. La bandera no dijo nada porque la bandera no existe. PALABRAS CLAVE sueños; acción oportunista; estigmergia; pensamento decolonial. 
Tenho mania de ver muito. Vi muitas entrevistas e lives de Krenak falando, sua fala de árvore e jabuti sempre me trazem as garras da onça a presas da onça, me sentia sempre silvestre e animal ao término das falas, e em uma dessas lives, ouvir: Krenak só faz live se sonhar que a fez, ele recebe o convite e se sonhar ele confirma, se não sonhar ele nega, pensei em quanto poderia entrelaçar minha vida com o sonho, me lembro de sonhar com os corredores da escola que só fui estudar depois de 5 anos do sonho ter acontecido. Me lembro de sonhar que dava o cu para alguém em um quarto que nunca tinha vida, depois de 7 dias dei para uma travesti nesse mesmo quarto, enquanto o pau dela estava dentro de mim, pensava no sonho e me sentia no passado, em um futuro já passado, ela me comia como quem devora uma manga, sem medo de fiapos no dentes. Krenak passando jenipapo na cara esperando não agredir um protocolo que o agride, quanta glória existe no caçador que saúda sua presa, desenha a caça no útero da terra, para que nela existam mais daquela que foi caçada, que virou comida. Quero muito ser comida e desenhada no útero da terra, nas paredes do meu útero está desenhado enormes cavalas, gigantescas éguas e búfalas e bixas da cara preta, e travas pretas, e vários transmasculinos, seres de bucetas que não se rivalizam e glorificam um novo mundo, um ritual está pintado na parede do meu útero.

\footnotetext{
<< esse trabalho é sobre isso, sabe, não só no contexto amplo, mas do sistema prisional também, quando a Dilma foi...sofreu impeachment eu comecei a anotar alguns sonhos que comecei a ter com esses símbolos do Estado brasileiro e...esse é o meu interesse, investigar como todas essas questões impactam o nosso inconsciente para além do discurso racional, para além do nosso dia-a-dia, para além do que a gente entende como nos impacta, sabe. Porque sonhos também tem essa ambiguidade né, coisas que passam pela sua cabeça,
} 
quando você está dormindo você tá processando e ao mesmo tempo é isso dos sonhos serem mais do que metas...enfim...tem essa ambiguidade. E eu acho que é uma maneira de...eu não digo humanizar as pessoas, mas é uma maneira de mostrar que todo mundo tem a sua profundidade, assim. Eu acho que sonho pra mim, o inconsciente pra mim é isso. São camadas mais profundas de relação, então a partir do momento que eu penso que todo mundo sonha ou que todo mundo já sonhou ou que todo mundo tem essas imagens muito loucas passando pela cabeça eu sei que todo mundo, pensei especificamente na minha bisa, especificamente a vó Paulina, que já faleceu há uns anos. Você olhava a vida dela, nossa, que vida pacatinha, assim sempre andando devagar, falando muito pouquinho, mas ela sonhava, ela também tinha essa profundidade de inconsciente... >>

Bom dia presidente Lula,

Boa tarde presidente Lula, Boa noite presidente Lula.

Os sonhos do Lula apareceram na minha mente enquanto eu ouvia as pessoas fazendo comida na frente da PF e gritando

Bom dia presidente Lula,

Boa tarde presidente Lula, Boa noite presidente Lula.

O que sonha o Lula?

Krenak sonha com Lives.

Com o que sonha o Lula?

Movimentos para se tornar uma presidenta

Dormi com a cara pintada de verde amarelo se cobrir com a bandeira do brasil deitar com a cabeça no cruzeiro do sul rasgar a bandeira, vestir os farrapos. dormi. 
Bom dia presidente Lula,

Boa tarde presidente Lula, Boa noite presidente Lula.

é muito bom pensar que jesus e barrabás são a mesma pessoa

é muito bom acessar barrabás e jesus de si

abel e caim

eva y adão

y a maçã y a cobra.

Com o que sonha o Lula? Krenak não sonhou com Live.

Os sonhos do Lula apareceram na minha mente enquanto eu ouvia as pessoas fazendo comida na frente da PF e gritando

Bom dia presidente Lula,

Boa tarde presidente Lula, Boa noite presidente Lula.

Com o que sonha o Lula?

Não quero pensar o brasil como país do futuro. não quero mais nenhum futuro. quero me desatar do passado. não quero recompensas pelas minhas boas ações nem castigo pelas minhas ruins. quero parar a frutificação horrivel da causa e consequência.

Isso aqui não é só um trabalho, é uma sondagem no escuro. Sonhando em mudar. Mudando pra sonhar. Depois recolhendo o que dá das não-imagens, não-significações, não-identidades. Tudo no sonho muda como na natureza,

todas as formas caminham para a indefinição. 
Percepção -> Ação pela Cognição Situada

Rituais Poéticos / Ações Oportunistas

As formigas não precisam de linguagem, não precisam de mapas ou memórias. Não existe para as formigas ensinamentos, nem transmissão.

Só cheiro.

Hormônio liberado quando acham comida. Quanto mais comida, mais forte o hormônio. E as outras seguem e fortalecem o rastro como seus cheiros. E assim

Todo mundo come

Sonhar para fazer todo mundo comer, que sonho bom!

AÇÃO OPORTUNISTA

COMPRAR UMA BANDEIRA DO BRASIL - DORMIR COMELADEBAIXO DO COLCHÃO-ESCREVER

\author{
< Comprei uma bandeira do Brasil \\ na Casa China e fiquei com vergonha \\ da atendente. Dormi com a bandeira \\ embaixo do colchão. A bandeira não \\ me disse nada.
}

Constatei por mim mesma que a bandeira do Brasil no interior de São

Paulo é só no templo dos coxas, o

templo de plástico. Havana. A liberdade

\begin{abstract}
que por aqui higienizou o bairro de
Puta acabando com o comércio de muitas, chegou até rolar agressão em uma das trabalhadoras do bairro por esses caras fardados e fadados a uma carreira curta, com cal e sal. Elá onde a Dama Liberdade faz ponto na esquina, é que encontrei a bandeira >>
\end{abstract}

O que eu estava pensando?

A bandeira é um pedaço de Pano. E as estrelas estão tortas.

O pedaço de Pano foi transformado num símbolo, contra a sua vontade. 
O Pano está confuso e cansado. O Pano viajou até aqui pra ser bandeira debaixo da minha cama. 0 tecido foi violado.

Não presenteamos um bebê recém nascido com uma bandeira, foi o que o Pano me fez pensar. O tecido é áspero. O que queria ter sido o Pano? A bandeira não disse nada porque ela não existe.

Com o Pano debaixo do colchão, sonhei com um objeto cortante saindo do ponto em que me cortaram durante a cirurgia.

O objeto metálico depois virava um aparelho de depilação, que virava depois um copo plástico com tampa e canudo. As médicas do SUS tinham esquecido o copo dentro de mim enquanto conversavam sobre a nova gravidez da Kylie Jenner. Elas disseram: queríamos ter nascido da barriga da Kylie. 0 médico assistente respondeu: Ainda dá tempo se você se matar agora, para reencarnar no bebê.

Essas foram as últimas palavras que eu ouvi antes de apagar com a anestesia.

Pano sem País, você tem alguma coisa a ver com esse sonho de corte?
AÇÃO OPORTUNISTA

POR A BANDEIRA NO SOL - SENTIR O CALOR DO PANO NO ROSTO - ASSOAR O NARIZ NA BANDEIRA

Tiro o celular da tomada antes de acabar toda a carga Já pensei em terminar com vc 4 vezes só hoje Não sei o que me impede de falar.

Sempre transformei silêncio em palavra

Escrever cartas de ódio

Escrever cartas de amor

Escrevo pois vc já dorme e eu não vim aqui para dormir sozinha.

Estou adiando o nosso fim por que eu não sei

Sou criativa

Imagino mil fins

1

- vamos terminar

Acredito que preciso fazer isso por nós duas

Você não teria coragem, Brasil.

Você prefere fixar os olhos na paisagem

no azul do céu, no verde das matas 
e no ouro.

E esconder de mim aquilo que na verdade é cemitério, terra saqueada,

sangue que sai da seringueira, sangue de Chico Mendes.

Não quero entrar na sua mente mas

Você mesma que me falou

"Ordem e Progresso"

como progredir sem tapar a hemorragia das balas.

Posso apenas te regar e deixar ir

2

-vamos terminar

Ao teu lado eu me sinto sozinha

Me agrada apenas seu braço forte em minha

cintura quando dormimos

em lugar que não é meu, em casas que não são minhas

em berços esplêndidos.

Gosto mais da gente dormindo

A vida nos quer acordada

RAIZ, Julia; MARÉ. Com o que sonha o Lula? Krenak sonha com lives.
Hoje não sei se irei dormir

Despertei com você e agora quero sair

Não sei nem porque vim. porque te chamar de Brasil

território que só em brasa queima.

que a árvore vermelha já não existe mais

Investigo deduzo e frito

Você mesmo já fritou e eu fiquei engordurada

Tomo uma Coca-Cola gelada para desentupir

Amor ruim

Pia entupida

Privada

Privatização

e Dívida Histórica.

Coca-Cola gelada cura até ressaca

Não pretendo beber para te esquecer

Quero é lembrar mais de mim

Ainda bem que lembrei

de ver a noite como um oceano

uma luta que vem para arrebatar

um olho que chora, apenas um olho que lacrimeja

e as gatinhas mortas 
A gatinha pariu

Transcreveu

Acreditou

Parece que me dói te deixar

Como se fosse desistir de nós

E se for? E se eu for?

Eu vou. Arranjo outros.

Ficcionar um outro país onde as vidas não caem

onde os corpos voam

onde a fera que se aproxima vem para comer o Jesuíta.

Desatou o nó da minha garganta

Desato o nó da minha garganta

Passo mel

Passo a entender o lugar de falha

isso mesmo um lugar de falha

Construo mantas de cura

Desato o nó da minha garganta
Como uma santa

E desatado o nois

3 - Vamos terminar!

Enrosco

Embromo

Embolada e amarração

Desfaço o nó coxo do meu coração

Desato o nó coxo de minha garganta

Não tenho medo das reações

Das suas, das minhas.

Eu não preciso temer

Conhecer e necessário

Navegar é preciso

Travecar y edificar a vida

Firmar seus alicerce em outra coisa

que não colunas vertebrais humanas.

Agraciar as rédeas da vida

Com comando de mares

Mares e sol

Maré e Mares 
$<<$ Entrei. Procurei. Imagine em qual departamento se coloca a bandeira do Brasil, o espanto. É o templo do horror! A bandeira do Brasil fica na moda masculina, do lado de camisas com frases patéticas e idiotas, em verde e amarelo. Efui ao caixa, pagar19,90 em um pedaço de pano que tem o peso de mais de 550 anos de história, milhares de hectares, ouro de garimpo e toneladas de corpos $>>$

\section{AÇÃO OPORTUNISTA}

SONHO COM R. - COM O QUE SONHAVA R. QUANDO ESTAVA LÁ? - QUE TRABALHO BONITO, SABE, VOCÊ ME EXPLICANDO NESSE ÁUDIO ACHO QUE EU ENTENDIMELHOR, FAÇA COMO VOCÊ QUISER TRANSCRIÇÃODE ÁUDIO

Então, eu sonhava, sonhava bastante os 9 meses que eu tava lá. Nos primeiros dias eu não conseguia dormir, eu tava assustada com o quanto tudo era feio e sujo. E ai nos primeiros dias eu dormi, não lembro assim, acho que demorou muito pra eu dormir, acho que eu fui dormir no sexto ou sétimo dia de cansada assim.
Eu tinha muito pesadelo. Eu via muita mulher sem dente, eu tinha muito medo de perder meus dentes então eu sonhava comigo banguela. E assim várias vezes eu acordava no meio da noite e contava os dentes, passava a língua pra saber se eles estão lá. E depois foi normalizando os meus sonhos assim, é, eu sonhava muito, eu fazia mentalização antes de dormir assim pra conseguir relaxar e pra deixar aquele lugar menos ruim, sabe. Ai eu sonhava com o que eu ia fazer quando eu saísse, que ia acabar, tinha sonhos sabe com jardins, com... eu tentava ser positiva assim.

Outra coisa, a gente revezava quando tava no barracão 2 os dias de quem ia dormir deitada, quem ia dormir em pé porque a cela era super lotada sabe. A gente dividia em 10, cabiam 6. Mas foi um período bem curto, eram uns 2 meses. E quando eu dormia em pé eu sonhava muito que eu tava num barco, que eu tava num ônibus, eu sentia um movimento acho que de...de desequilibrando, de dormir, eu tinha esse tipo de sonho. eu sonhava muito com a minha família, eu tinha muito pesadelo também de sair e as pessoas que eu...que meus avós tivessem morrido, que eu não fosse ver nunca mais. Eu também tinha pesadelo com as pessoas não falando comigo, mas eu tinha sonhos também que as pessoas iam estar me esperando e que ia dar tudo certo. 
Ah, eu tinha uns sonhos bem loucos assim, isso que eu nem passei muito tempo né, foram 9 meses. Mas eu imaginava que quando eu ia sair o mundo ia estar meio os Jetsons, já ia ter carro voador, umas coisas assim.

Quando iam fazer inspeção com cachorro, eu sonhava com cachorro à noite, sabe. E não era um sonho negativo assim, era meio que a repetição da cena, sabe. Ah, eu tinha muito pesadelo no começo assim...

Minha mãe me ligou, desculpa. Então, eu me impressionava muito com a sujeira, eu tinha muito pesadelo assim e sonhava assim com a sujeira de lá de uma maneira mais exagerada. Até hoje eu tenho pesadelo, com a sujeira principalmente. Eu sinto que estou num lugar sujo, que não consigo sair. Que tem barata e rato, que aquele cheiro de comida recozida às vezes vem. Hoje é o tipo de pesadelo que eu tenho e eu tenho muito pesadelo de assim, sei lá, nunca mais passar essa história, sabe. Sempre ser a menina que passou por isso. Sempre ser a mulher que passou por isso. Nunca evoluir na vida por causa disso, assim. Mas eu acho que esse é um sonho bem consciente porque acordada eu também tenho.

E hoje quando eu penso nas mulheres que dividiram cela, assim, que eu convivi, às vezes eu sonho com elas. Algumas... a maioria eu perdi contato e eu sonho com o que elas me contavam, se elas realizaram ou não, enfim...eu sei que eu estou falando de depois, acho que vocês queriam enquanto eu tava lá dentro.

E eu lembrei que eu esqueci de dizer que quando tinha rebelião na prisão dos macho e que dava pra ouvir porque era na mesma quadra eu tinha muito pesadelo com isso. Eu tinha muito medo que virasse a nossa Piraquara ali, sabe. Era uma coisa que me assustava, era uma coisa que me vinha recorrente assim.

\section{AÇÃO OPORTUNISTA}

SENTAR NO CHÃO NO ESCURO - COLOCAR A BANDEIRA EM CIMA DA CABEÇA COBRINDO OS OLHOS - PSICOGRAFAR MENSAGEM DA BANDEIRA [O PANO] - SONHAR - ESCREVER O SONHO

MUITO SANGUE.

PEDAÇOS DE PESSOAS CRESCENDO

EM ÁRVORE

EXIBIR PESSOAS QUE

FORAM MORTAS 
O AMARELO ESCORRE

O VERDE ESCORRE

AS ESTRELAS GRUDAM NA

SUA CABEÇA

O QUE VOCÊ QUER SABER?

ESQUECE O QUE VOCÊ ACHA

QUE SABE SOBRE ESSA

TERRA

VOCÊS NÃO SABEM DE NADA

QUEM FAZ ESSA TERRA SÃO FUNGOS E BACTÉRIAS QUE

DECOMPÕEM OS MORTOS

NÃO EXISTEM MORTOS

EXISTE COMIDA

LÁ EMBAIXO TODO MUNDO COME.

SEUS OLHOS ESTÃO PESADOS

VOCÊ TEM UM PAÍS

NA CABEÇA E ELE NÃO

É O QUE VOCÊ PENSA

SONHE FUNGOS E BACTÉRIAS
PEÇA PARA ELAS A INTELIGÊNCIA

QUE VOCÊ NÃO TEM.

SEUS OLHOS ESTÃO ARDENDO

SÃO AS ESTRELAS

FERINDO SEUS OLHOS

A PALAVRA ORDEM A PALAVRA

PROGRESSO SÃO SÓ UNS

RISCOS

VOCÊS TÊM MEDO DE

TUDO

ATÉ DOS RISCOS

SE O VERDE PEGAR FOGO

SUA CABEÇA VAI PEGAR

$\mathrm{FOGO}$

SE O AMARELO ESCORRER

VAI AGARRAR NA SUA CABEÇA

E O AZUL? O AZUL SAI

ROLANDO E ROLANDO PRA SEMPRE 
COM O BRANCO VOCÊ MESMA FAZ UMA FAIXA

PRA TAPAR SUA BOCA

NÃO PENSE MAIS

OLHA PRA MIM! VOCÊ TEM

CORAGEM? EU SOU UM

PANO! VOCÊTÁ COM UM

PANO NA CABEÇA. PAÍS, BANDEIRA, ESTRELA

ISSOÉ TUDO

COISA DA SUA CABEÇA!

um corpo meio arroxeado, meio verde, que tentava falar e só água saia da sua boca

eu não senti medo, eu não sentia medo,

eu tentei olhar para ele nos olhos,

mas seus olhos cheios de veias vermelhas,

desviava do meu,

desviava,

não me encarava,

sentia vergonha de si?

Agachou no chão que era terra,

terra barrosa, pegou um pedaço de barro, e pôs na boca.
Não sei se essa bandeira é a perfeita por ser a mais imperfeita formulação de ordem e progresso.

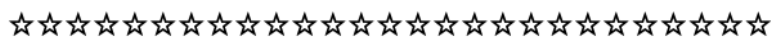

Atravessei uma ponte de tábua por cima de um córrego. Cheguei na boca da floresta, entrei. Lá dentro estão vagando um grupo de pessoas mais velhas, em transe. Encontrei uma mulher e uma criança sentadas no chão e um quati. O quati tem duas grandes presas igual um javali. Na mata tem portas que eu posso entrar e sair. Preciso tomar cuidado por onde entro ou saio para não deixar o quati se sentir acuado porque ele pode me atacar. Do outro lado da ponte de tábua, da onde eu vim, desmontam o Brasil como uma casa antes da mudança.

AÇÃO OPORTUNISTA

SE COBRIR COM A BANDEIRA - ESPERAR ALGO ACONTECER

Ao me cobrir com o manto, percebo quanto é vagabundo seu tecido, viajo por camisa da seleção, coxas de jogadores y Marta. Quantas releituras apropriadas, quanto mais penso que Pelé se tornou 
um símbolo e um local, que sua música abc ABC toda criança tem que ler e escrever, ainda útil, ainda sendo uma nação que analfabeta da língua portuguesa, lingua cobrada pelo regime de Portugal, hoje peleja para recordar a língua de seus povos, de valorizar aqueles que falam o ritmo.

Pretoguês que existe, amém, obrigada por nos afastar daquela enrolação de língua que os portugueses têm.

Fui dormi e não sonhei com nada, repeti a ação no dia seguinte antes de dormi, não tive vontade de escrever nada.

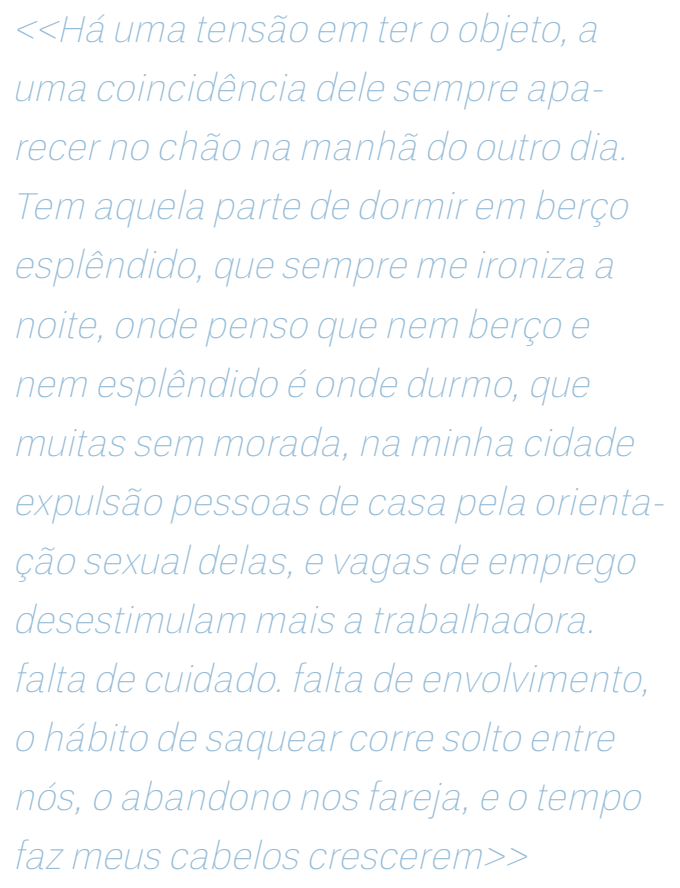

\section{AÇÃO OPORTUNISTA}

COMER BANANA EM CIMA DA BANDEIRA - DEIXAR AS CASCAS CAIREM - AMARRAR A BANDEIRA COMO UMA TROUXA DEROUPAS, AS CASCAS DENTRO - POR A TROUXA EM CIMA DA CABEÇA.

Nosso discurso político é teopolitico.

O mito uma cortina, o mito uma fundação.

A versão do mito

futuro do presente

Necessidade de conhecer o passado.

O presente é constituído pelas forças que estão em ação há pelo menos 500 anos.

Tirar o mito da frente.

Estratégico.

Fazer um mito com pedaços da realidade.

Pedimos um passado que não conhecemos. Ignorante.

Combater a ignorância no imaginário.

Combater a ignorância que não imagina

Não lutar pela repressão como se estivesse lutando pela liberdade. 
As meninas sempre estiveram certas

Bom Xi bom Xi bom bom bom

Onde o rico cada vez fica mais rico.

E o pobre cada vez fica mais pobre.

Mal sabia as meninas que pobres iriam acreditar que eram ricos.

E o ricos iriam costurar, uma bandeira, um mito, uma fundação que não revelasse a Fundação.

Feita em cima de uma pluralidade, que morta, ainda continua

Continua a pulsar na terra clamando por uma reviravolta.

Uma bandeira delimita um campo

Um território.

um povo pasteurizado não dá conta de um país

A Pluralidade que não dá para ser reduzida.

E se reduzida, o cachimbo bate no touro, que bate na gente

acabou-se o mundo.
AÇÃO OPORTUNISTA

ENCARAR A BANDEIRA - ENCARAR A SI MESMA TAMPAR SUA IMAGEM COM A BANDEIRA - OLHAR EAGUARDAR

A bandeira verde e amarelo. Símbolo, qual é a história dessa bandeira?

O que é?

O verde é a desesperança, o amarelo a tristeza, aí o azul não sei...

os memes contam a história melhor que o mito.

As cores de nossa bandeira são as cores de nossos colonizadores.

A gente se vende

Se venda

Revende

Caminha a supor um lugar final

Lema positivista.

Bandeiras não são só bandeiras

Cores não são só cores.

O projeto de extermínio

E toda América passou por isso e nossos vizinhos contam a história e a gente não conta 
Dizimadas

Dízimos

Dizimadas nas ruas

Dizimadas

Monocultura subjetiva

Só produzindo um modo de ser

violento que danifica o solo

Que mata o que diverge

Transformando florestas em pasto pra boy-escroto pastar

Acumula no coração dos outros a vontade de ser rico e admirado.

"Todo mundo quer comandar e não ser comandado" disse o filósofo se esquecendo das práticas bdsm.

Multidão

Guerra

Essa é a bandeira de nossa guerra

A história do Brasil é eke atrás de eke.
Entender e deixar de jogá-lo

Como fazer isso jogando.

Combate público velado

Cuidado maiores

Cuidado menores

Capacidade de respirar

Reservas de paciência e calma para

continuar lutando

Reservas de ódio e raiva já abarrotados e lotados.

Continuar alegre mesmo que se lute contra o absurdo que está ganhando.

A história conecta coisas

A teia da aranha

Questionar aquilo que se dá como uma certeza.

Realmente um pensamento estreito passa por mim:

O mito subsistindo a realidade? Ou a realidade é uma construção de vários mitos? 
$<<$ Ainda me irrito ao ver que compa-

ram crianças com presidentes. Onde o absurdo se torna possivel, e se possivel fosse uma criança na presidência, tenho pra mim que ela tomaria a realidade a duras goladas, mas jamais arriscaria tudo só pelo seu egoísmo. Crianças são egoístas mas não são tolas. Erês ensinem a eles que criança bixo-gente sábio, que a anciã é sábia,

Ensina para nós Erês, o que já é sabido: Quem planta o terror, a morte colhe, >>

Os mitos podem cristalizar como se fossem uma crença ou a realidade. O mito pode tornar a realidade existente invisível. Os fatos não importam, o que importa é como esses fatos são contados sem comprometimento com a verdade. A bandeira, simplesmente não existe.

Antônio Bandeira assim como eu

também diria

que signo, gesto y ação são tecnologias

A ser humana é muito ardilosa

para se unir foi capaz de muito criativa inventiva

hasteou pedaço de tecido as alturas

Fez mais de uma

criou para se identificar

Pelotão

Reinado

Países

Estados

Identidades

É muito mais

Bandeiras e eu

Se um dia nos beijarmos

Vamos nos decepcionar

Tem vivas que não encaixam

Tem dedos que se assustam com o entrelaçar

e ficam desconfortáveis

Tem desconfortos que são toleráveis

é sempre bom ter para quem dá a azeitona

Uma pessoa da minha família, sai de uma cozinha que não conheço, passa por mim que estou sentada em uma sala que não conheço, é uma casa 
desconhecida, que nas paredes tem retratos, fotos de família tradicional, a pessoa se senta na minha frente, diz frases confusas

"Você irá destruir sua família"

"Você impedirá a continuidade de nossa família"

"você é culpada"

Me encontro parada, querendo falar, mas continuo calada, até que líquido dourado parecendo seiva de árvore começa a sair da minha boca, tento evitar, mas não consigo, abro a boca em ato de entrega, a sala desconhecida começa a se encher de seiva, âmbar por toda a sala, a pessoa continua a falar como se não visse que estou a vomitar, a virar uma fonte de seiva, um gosto doce vai surgindo em minha boca, a seiva já bate em minhas canelas, e da minha boca a seiva não para, continua a cair, pelos cantos da boca quando fecho a boca, e assim que abro sai um jorro forte, meu corpo fica estranho, me sinto bem e ao mesmo tempo como se estivesse queimando em febre. A seiva já toca meus joelhos, me levanto e percebo que não tem mais ninguém naquela sala comigo, começo a andar pela casa que é feita de corredores estreitos, a seiva está por todos os lados, ando com uma certa dificuldade pois a seiva é expeça, chego no quintal; e ao abrir a porta a seiva começa a sair, conquista o quintal com o andar do mel, devagar e espesso, percebo que já não sai da minha boca nada, que conheço aquele quinta, onde uma mangueira grandiosa balança seus galhos mesmo sem vento, ao me aproximar algo sussurra no meu ouvido

"Não tenha medo, o fim é só um outro começo"

\section{AÇÃO OPORTUNISTA}

COM UM TOPE DO BRASIL E CALCINHA, SAMBARE CANTAR MÚSICAS ROMÂNTICAS DA MPB

O verde pertence a casa de Bragança, de Dom Pedro 1

O amarelo vem da casa da Imperatriz Maria Leopoldina.

O Azul, do traço cínico e canalha que força a religião católica para

as indígenas e justifica a escravização dos povos africanos.

Permanece deitado em um berço esplêndido um beber engasgado e roxo, Brasil.

Jardim sem futuro. Sem passado.

Permanece acreditando em um sonho gigante, um sonho gigante. 
As nossas revoluções reduzidas a uma baderna.

Um sintoma

O sintoma de uma cultura nacionali lobotomizada, encarcerada, acostumada a esquecer, desgastada, cansada e forçada a ouvir anedotas.

Dizem que nós não podemos aceitar,

A paz ao preço da violência,

o preço de justificar a violência.

Há uma prática de pacificar,

uma ideia de profano para justificar a violência do

purificar.

Colocar as coisas em ordem

O modo de funcionamento: Destruição.

A República das Espadas, Marechal Deodoro da

Fonseca

e seu grande cuzão que declama o hino.

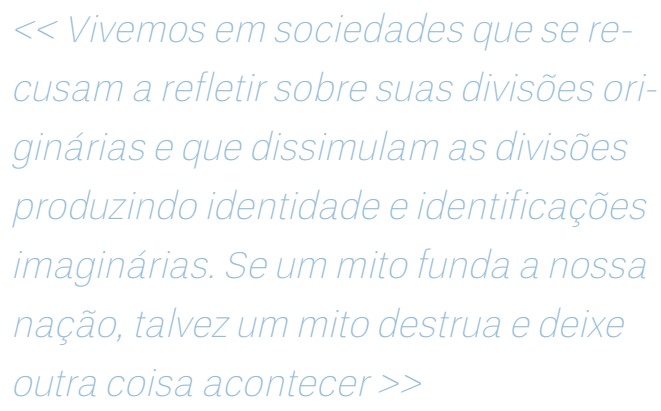

$<$ Vivemos em sociedades que se recusam a refletir sobre suas divisões originarlas e que dissimulam as divisoes produzindo identidade e identificaçoes
$<<$ Não podemos desejar nenhum tipo de retorno,

o fato para além do mito.

Queremos o real sem doer em ninguém>>

: Marilena me encarava com seus olhos de Erê.

Como naturalizar o sonho?

Como pôr em curso um sonho?

Nós somos uma consciência encarnada em corpo que não tem pura consciência.

Não somos pensamento puro. E nem puro somos.

O mundo não é um conjunto de fatos causais e funcionais,

além do mundo existe um mundo como lugar que vivemos com as outras, um mundo cheio de camadas e caminhos, lembranças, afetos.

Um mundo de conflito, esperança e paz. somos seres temporais, no tempo.

Seres especiais. A mata. O campo. O céu. O mundo espacial. Dimensões. Grandes pequenas. O corpo não é um feixe, e nem uma rede. O meu corpo é um sensível que é sensível para si. 
Atopia

Acronia

O Fordismo é quando uma empresa detém e controla a ponta inicial e a ponta final.

Ela é um pequeno planeta.

Ao ouvir Zâmbina falar sobre a confiança que se tinha na confiança do PT no órgão público, no funcionamento do estado, me pareceu óbvio que o ataque seria nesse ponto, fazendo parecer que nem mesmo o PT foi honesto no poder.

Tem mais lógica ir em uma benzedeira do que ler a República de Platão.

\section{AÇÃO OPORTUNISTA}

SE MASTURBAR E GOZAR NA BANDEIRA - TRANSAR

EM CIMA DA BANDEIRA

Desafogar mágoa rasteira

Gozar feitiços secretos

Conta as pedras da aruanda. Somar o número em prosperidade

Ser o céu, voar em si, navegar em universos.

Calma

\section{Paciência}

Destreza

Prazer em ser imperfeita

Perfeita forma de prazer

Treinadora

Treinada

Traiçoeira

Mandingueira

Maria Mandinga

Maria Mulambo 
Padilhas e tranca rua.

As travas nas ruas são mais santas que as estátuas

no altar.

Na estigmergia não existe planejamento prévio, mas um encadeamento de ações que puxam outras ações. As formigas nos mostram sem se importar com a gente. A gente vai lá e faz para dar início ao Ritual [Ação Oportunista], dá um passo atrás pra ver o que aconteceu e depois faz de novo.

Aqui sonhamos como gente e trabalhamos como formigas. Partimos do princípio de Estigmergia. 